\title{
MODEL PENANGGULANGAN MANAJEMEN STRES KERJA PADA LINGKUNGAN PENDIDIKAN
}

\author{
Rita Aryani ${ }^{1}$ Yudin Citriadin $^{2}$ Lalu Muhamad Ismail $^{3}$ \\ ${ }^{1}$ Universitas Panca Sakti Jakarta \\ ${ }^{2}$ Universitas Islam Negeri Mataram. Jl. Gajah Mada Jempong Mataram \\ ${ }^{3}$ Dinas Dikbud Kab. Lombok Tengah, Jl. Ahmad Yani 21 Praya \\ Email: ${ }^{1}$ ritaar1757@gmail.com ${ }^{2}$ yudin.citriadin@uinmataram.ac.id ${ }^{3}$ laluismail1968@gmail.com
}

\begin{tabular}{|c||c||c||c|}
\hline Received & Submit & Edited & Published \\
\hline 01 September 2020 & 31 September 2020 & 31 Desember 2020 & 31 Desember 2020 \\
\hline
\end{tabular}

\begin{abstract}
ABSTRAK
Tujuan dari penelitian ini adalah untuk menguji manajemen stres di tempat kerja, mengoreksi temuan penelitian terkait dengan manajemen stres kerja di lingkungan pendidikan. Tulisan ini menggunakan pendekatan kualitatif dengan metode studi sastra. Teknik analisis yang digunakan adalah kombinasi analisis isi kronologis sesuai dengan literatur/literatur yang sedang dipelajari. Hasil penelitian, bahwa beberapa peradaban saat ini terasa semakin berat dan tampak kejam, dan membuat semua orang berusaha untuk berjuang lebih keras dan tidak pernah menyerah untuk menaklukkannya. Salah satu faktor pemicu terjadinya stres di lingkungan kerja adalah faktor pribadi, faktor organisasi, dan faktor lingkungan. Cara untuk mengelola stres kerja adalah program klinis, program organisasi, dan penanggulangan secara independen. Dampak dari makalah ini adalah untuk mengurangi tingkat stres dan menghindari bunuh diri.
\end{abstract}

\section{Kata Kunci: Manajemen Stres, Tempat Kerja, Lingkungan Pendidikan}

\begin{abstract}
The purpose of this study is to examine stress management at work, correct research findings related to work stress management in the educational environment. This writing uses a qualitative approach with a literary study method. The analysis technique used is a combination of chronological content analysis in accordance with the literature/literature being studied. The results of the study, that some civilizations are currently felt increasingly heavy and seem cruel, and make everyone try to fight harder and never give up to conquer it. One of the factors triggering the occurrence of stress in the work environment is personal factors, organizational factors, and environmental factors. Ways to manage work stress are clinical programs, organizational programs, and countermeasures independently. The impact of this paper is to reduce stress levels and avoid committing suicide
\end{abstract}

Keywords: Stress management, Workplace, Educational Environment

\begin{tabular}{|c|c|c|c|c|c|c|}
\hline $\begin{array}{c}\text { Volume } \\
11\end{array}$ & Nomor & Edisi & P-ISSN & E-ISSN & DOI & Halaman \\
\hline
\end{tabular}




\section{PENDAHULUAN}

Stres merupakan istilah yang berasal dari bahasa latin stingere yang berarti "keras". Istilah ini mengalami perubahan seiring dengan perkembangan penelaahan yang berlanjut dari waktu kewaktu dari straise, strest, stresce, dan stres. Stres merupakan suatu keadaan dimana seseorang mengalami ketegangan karena adanya kondisi-kondisi yang memengaruhi dirinya. Stres merupakan respons dari diri seseorang terhadap tantangan fisik maupun mental yang datang dari dalam atau luar dirinya. Keadaan ini akan selalu terjadi dalam kehidupan manusia karena hal itu merupakan bagian dari dinamika perjalanan hidup. Oleh karena itu, selama kehidupan berlangsung, tidak mungkin manusia terhindar dari stress. ${ }^{1}$

Istilah stres dan depresi sering tidak dapat dipisahkan satu dengan lainnya. Setiap permasalahan kehidupan yang menimpa diri seseorang (stresor psikososial) dapat mengakibatkan gangguan fungsi/faal organ tubuh. Reaksi tubuh (fisik) ini dinamakan stres, dan manakala fungsi organ-organ tubuh itu terganggu terjadilah distress. ${ }^{2}$

Stres baik fisik maupun mental akan memberikan dampak terhadap dinamika perilaku seseorang, bergantung pada cara ia menghadapi kondisi yang menimbulkan stres. Dengan demikian, reaksinya dapat bervariasi antara orang yang satu dan lainnya, baik dalam jenis maupun intensitasnya. Namun, stres tidak selalu mempunyai pengertian negative, artinya tidak selalu berdampak negatif. Sementara itu, pada orang tertentu dan dalam kondisi tertentu, stres dapat menimbulkan hambatan dan gangguan tertentu baik fisik maupun mental. Stres yang bersifat positif disebut eustres, sedangkan stres bersifat negatif disebut distress. ${ }^{3}$

Dampak psikologi dari stres yang kuat adalah kecenderungan gampang marah, frustasi, kecemasan, agresif (menyerang), gugup dan panik. Keadaan lebih lanjut adalah timbulnya kebosanan, apatis, depresi, tidak bergairah, dan kehilangan kepercayaan diri. Dampak stres yang bersifat jasmaniah, antara lain perubahan hormonal, tekanan darah tinggi, meningkatnya denyut jantung, kesulitan pernapasan, gangguan pencernaan saraf, dan sebagainya. Dampak stres terhadap perilaku, erat kaitannya dengan dampak psikologis dan jasmaniah. Dalam aspek perilaku, stress dapat menimbulkan berbagai

\footnotetext{
${ }^{1}$ Nasrudin, H. Endin, Psikologi Manajemen (Bandung: Pustaka Setia, 2010),

${ }^{2}$ Bastaman, H.D, Psikologi untuk Menemukan Makna Hidup dan Meraih Hidup Bermakna (Jakarta: Raja Grafindo, 2007),

${ }^{3}$ Surya, Mohammad, Bunga Rampai Psikologi Manajemen (Bandung: Ilham Jaya, 1994),
}

\begin{tabular}{|c|c|c|c|c|c|c|}
\hline $\begin{array}{c}\text { Volume } \\
11\end{array}$ & Nomor & Edisi & P-ISSN & E-ISSN & DOI & Halaman \\
\hline
\end{tabular}


gejala kelainan perilaku, seperti kurang mampu membuat keputusan, mudah lupa terlalu peka, pasif, kurang tanggung jawab, acuh, dan seterusnya. Dampak selanjutnya adalah dalam aspek lingkungan baik dalam lingkungan keluarga, lingkungan kerja, organisasi, maupun lingkungan masyarakat. Terjadinya job stres yang disebabkan oleh sumbersumber stres yang berasal dari organisasi dan individu merupakan faktor yang mempengaruhi kepuasan kerja dan kinerja karyawan. ${ }^{4}$

Tanda-tanda atau gejala stres pada umumnya dapat dikelompokkan sebagai berikut: (1) Aspek emosional (perasaan). meliputi: merasa cemas (feeling anxious), merasa ketakutan (feeling scared), merasa mudah marah (feeling irritable), merasa suka murung (feeling moody) dan merasa tidak mampu menanggulangi (feeling of inability to cope); (2) Aspek koginitf (pikiran). Meliputi: penghargaan atas diri rendah (low self esteem), takut gagal (fear failure), tidak mampu berkonsentrasi (inability to concentrate), mudah bertindak memalukan (embarrassing easily), khawatir akan masa depannya (worrying about the future), mudah lupa (forgetfulness), dan emosi tidak stabil (emotional instability); (3) Aspek perilaku sosial. Meliputi: jika berbicara gagap atau gugup dan kesukaran bicara lainnya (stuttering and other speech difficulties), enggan bekerja sama (uncooperative activities), tidak mampu rileks (inability to relax), menangis tanpa alasan yang jelas (crying for no apparent reason), bertindak impulsive atau bertindak sesuka hati (acting impulsively), mudah kaget atau terkejut (startling easily), menggertakkan gigi (grinding teeth), frekuensi merokok meningkat (increasing smoking), penggunaan obat-obatan dan alkohol meningkat (increasing use of drugs and alcohol), mudah celaka (being accident prone), dan kehilangan nafsu makan atau selera makan berlebihan (losing appetite or overeating); (4) Aspek fisiologis. Meliputi: berkeringat (perspiration/sweaty), detak jantung meningkat (increased heart beat), menggigil atau gemetaran (trembling), gelisah atau gugup (nervous), mulut dan kerongkongan kering (dryness of throat and mouth), mudah letih (tiring easily), sering buang air kencing (urinating frequently), mempunyai masalah dengan tidur (sleeping problems), diare/ketidaksanggupan mencerna/muntah (diarrhea/indigestion/vomiting), perut melilit atau sembelit (coil around in stomach), sakit kepala (headaches), tekanan

\footnotetext{
${ }^{4}$ Setyono, Agus; Mudji Rahardjo; Rini Nugraheni; Edi Rahardja. 2007. Analisis Faktor-faktor yang Mempengaruhi Job Stres Serta Pengaruh Terhadap Kepuasan Kerja dan Kinerja Salesmen (studi kasus pada PT. Adira Finance Cabang Bangkong Semarang). Jurnal Studi Manajemen \& Organisasi. 4 (2) http://ejournal.undip.ac.id/index.php/smo. 2020.03.9.
}

\begin{tabular}{|c|c|c|c|c|c|c|}
\hline $\begin{array}{c}\text { Volume } \\
11\end{array}$ & Nomor & Edisi & P-ISSN & E-ISSN & DOI & Halaman \\
\hline
\end{tabular}


darah tinggi (high blood preasure), dan sakit pada leher dan atau punggung bawah (pain in the neck and or lower back). ${ }^{5}$

Bila anggota suatu lingkungan banyak mengalami hambatan atau gangguan karena dampak stres, lingkungan pun akan terpengaruh sehingga menjadi lingkungan yang kurang sehat. Gejala-gejala seperti itu, misalnya suasana rumah tangga yang kurang harmonis, lingkungan pekerjaan yang kurang produktif, masyarakat yang tidak tenteram, dan sebagainya.

Hal ini mengarah pada pentingnya dilakukan sebuah intervensi untuk mengelola dan menangani stres, sehingga setidaknya kondisi penuh stres dapat berkurang. Manajemen stres adalah suatu program untuk melakukan pengontrolan atau pengaturan stres dimana bertujuan untuk mengenal penyebab stres dan mengetahui teknik-teknik mengelola stres, sehingga orang lebih baik dalam menangani stres dalam kehidupan. ${ }^{6}$

\section{METODE}

Artikel ini dibuat dengan menggunakan metode studi pustaka melalaui analisis konten pada berbagai makalah, buku, jurnal-jurnal baik hasil riset maupun konseptual mengenai manajemen stress, khususnya mengenai model manajemen stress di kalangan masyarakat sebagai salah satu learning outcomes.

\section{HASIL DAN PEMBAHASAN}

Faktor Pemicu Terjadinya Stres di Tempat Kerja

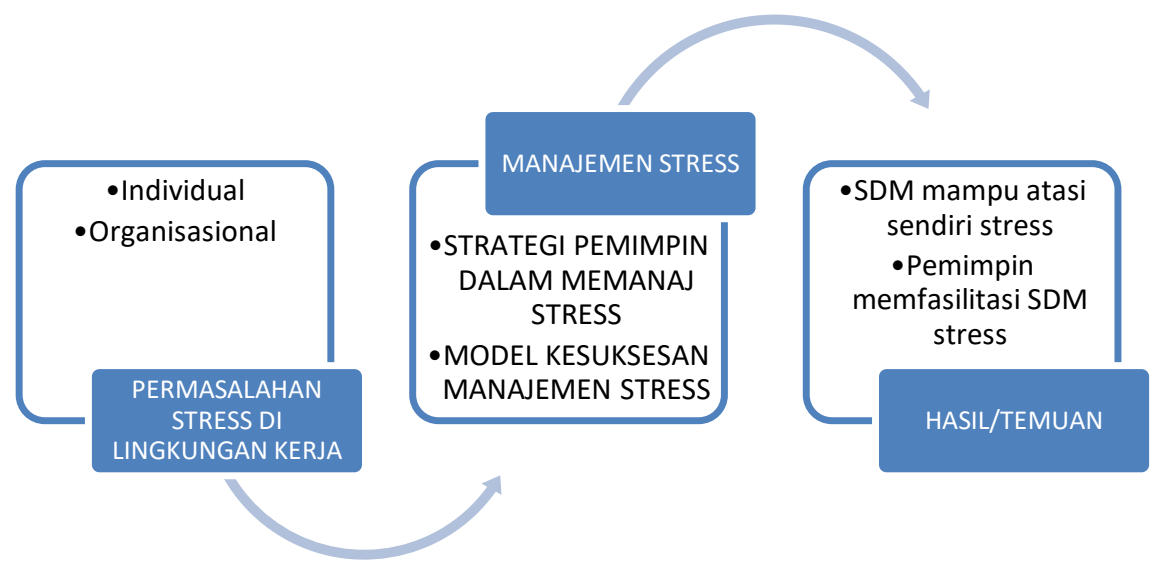

Gambar 1: alur model manajemen stress pada lingkungan kerja

\footnotetext{
5 Agoes, A, Teori dan Manajemen Stress (Kontemporer dan Islam) (Malang: Taroda, 2003),

${ }^{6}$ Schafer, Walt, Stress Management for Wellness: Fourth Edition (United State of America: Wadsworth, 2000),
}

\begin{tabular}{|c|c|c|c|c|c|c|}
\hline $\begin{array}{c}\text { Volume } \\
11\end{array}$ & Nomor & Edisi & P-ISSN & E-ISSN & DOI & Halaman \\
\hline
\end{tabular}


Ada tiga kelompok utama pemicu stres (biasa disebut stresor) di tempat kerja yaitu (1) faktor pribadi, seperti: keluarga, ekonomi rumahtangga, dan karakteristik kepribadian. Adanya persoalan pada kehidupan pernikahan, perceraian serta anak-anak yang tidak disiplin dan sulit diatur; penghasilan yang kurang mencukupi pemenuhan kebutuhan rumahtangga dan gaya hidup; serta kepribadian yang tertutup, mudah tersinggung, perfeksionis, sangat berorientasi pada waktu dan hasil, merupakan beberapa contoh faktor pribadi yang dapat menjadi pemicu terjadinya stres di tempat kerja; (2) faktor organisasi, seperti: pekerjaan, peran, dan dinamika hubungan atau interaksi antar karyawan. Pekerjaan yang bersifat rutin, monoton, membutuhkan kecepatan dalam pengerjaan, dengan ruang atau lokasi kerja yang bising dan panas; tuntutan peran yang tidak jelas atau bertentangan dengan sistem nilai yang dianut; serta hubungan kerja antar rekan yang tidak cocok, apalagi bila diwarnai dengan adanya konflik mental maupun fisik, merupakan beberapa contoh faktor organisasi yang dapat menjadi pemicu terjadinya stres di tempat kerja. Selain itu juga budaya tempat kerja yang sangat menekankan individualisme dan persaingan, struktur organisasi dengan kontrol dan komando yang ketat, kurangnya penguasaan terhadap teknologi yang digunakan, serta perubahan-perubahan yang terjadi secara cepat di dalam perusahaan; (3) faktor lingkungan, seperti: ekonomi, politik, dan teknologi. Ketidakpastian kondisi politik, krisis ekonomi negara yang berkepanjangan, serta perkembangan teknologi yang mengancam kelangsungan kerja merupakan beberapa contoh faktor lingkungan yang dapat menjadi pemicu terjadinya stres di tempat kerja.

\section{Cara Mengelola Stres Kerja}

Seorang pemimpin yang arif tidak pernah mengabaikan masalah pergantian karyawan dan keabsenan, penyalahgunaan obat-obatan ditempat kerja, penurunan prestasi, penurunan kualitas produksi, atau setiap tanda yang menunjukkan bahwa sasaran prestasi organisasi tidak tercapai. Pemimpin yang efektif memandang kejadian ini sebagai gejala dan melihat dibelakang gejala tersebut untuk mengidentifikasi dan mengoreksi sebab-sebab yang mendasarinya. Namun, kebanyakan pemimpin masa kini masih mencari kemungkinan sebab-sebab tradisional, seperti jeleknya pelatihan (training), peralatan yang rusak, atau tidak memadainya instruksi tentang hal-hal yang perlu dikerjakannya. Berdasarkan semua kemungkinan tersebut, stres tidak termasuk

\begin{tabular}{|c|c|c|c|c|c|c|}
\hline $\begin{array}{c}\text { Volume } \\
11\end{array}$ & Nomor & Edisi & P-ISSN & E-ISSN & DOI & Halaman \\
\hline
\end{tabular}


dalam urutan daftar kemungkinan masalah. Jadi, langkah yang paling pertama dari program penanggulangan stres ialah mengakui bahwa stres itu ada, sehingga langkah tersebut masih tetap di dalam batas yang dapat ditolerir. Setiap program intervensi untuk mengatasi stres harus menentukan terlebih dahulu ada tidaknya stres dan penyebab keberadaannya.

Stress pada awalnya dipakai nama seperti kesehatan mental, tetapi untuk menghindari pengertian penyakit psikiatrik yang serius, maka diubah nama programnya yang popular sekarang ialah manajemen stres. Dua program cikal bakal manajemen stres yang sering digunakan ialah klinis dan keorganisasian.

Program Klinis. Program ini penanggulangannya didasarkan atas pendekatan medis tradisional. Beberapa unsur dari program tersebut mencakup: (1) Diagnosis. Orang yang mempunyai masalah meminta pertolongan. Orang atau petugas pada unit kesehatan karyawan mencoba mendiagnosis masalah; (2) Pengobatan (treatment). Disediakan penyuluhan atau terapi dorongan. Jika staf dalam perusahaan tidak dapat menolong, karyawan tersebut dianjurkan berkonsultasi kepada ahli di lingkungan tersebut; (3) Penyaringan (screening). Pemeriksaan individu secara berkala dalam pekerjaan yang penuh dengan ketegangan diadakan untuk mendeteksi indikasi masalah secara dini; (4) Pencegahan (prevention). Pendidikan dan bujukan dilakukan untuk meyakinkan karyawan yang mempunyai pekerjaan dengan resiko besar bahwa sesuatu harus dilakukan untuk menolong mereka menanggulangi stres.

Program klinis harus ditangani oleh orang yang berwenang jika dimaksudkan untuk menyediakan kemanfaatan. Kepercayaan dan rasa hormat harus ditanamkan untuk memanfaatkannya. Ini dimungkinkan jika ada karyawan yang memenuhi syarat untuk melakukan diagnosis, pengobatan, penyaringan, dan pencegahan.

Program Keorganisasian. Program keorganisasian ditujukan lebih luas meliputi seluruh karyawan. Kadang-kadang program ini merupakan perluasan program klinis. Program tersebut sering didorong oleh masalah-masalah yang ditemukan dalam kelompok atau suatu unit, atau oleh perubahan penangguhan seperti relokasi tempat kerja, atau pemasangan peralatan baru. Berbagai program dapat digunakan untuk mengatasi stres, termasuk dalam daftar program semacam itu ialah manajemen berdasarkan sasaran (management by objectives), program pengembangan organisasi, pemerkayaan pekerjaan, perancangan kembali struktur organisasi, pembentukan

\begin{tabular}{|c|c|c|c|c|c|c|}
\hline $\begin{array}{c}\text { Volume } \\
11\end{array}$ & Nomor & Edisi & P-ISSN & E-ISSN & DOI & Halaman \\
\hline
\end{tabular}


kelompok kerja otonom, pembentukan jadwal kerja variabel, penyediaan vasilitas kesehatan karyawan.

Berdasarkan uraian di atas, hasil penelitian Brotheridge ${ }^{7}$ mengungkapkan bahwa sebagai sarana efisien menguji kesehatan relatif model ini, 3 variabel yang berhubungan dengan pekerjaan yang mewakili subset dari semua kemungkinan mekanisme koping, stres, dan strain (dukungan rekan kerja, beban kerja, dan kelelahan emosional masingmasing) bekerja. Hasil penelitian menunjukkan bahwa mengatasi sumber cenderung untuk melayani pencegah sebagai langsung saring dan, dengan demikian, adalah mekanisme pemeliharaan kesehatan umum independen dari tingkat pra ada stres.

\section{Stres dapat Ditanggulangi Sendiri}

Hasil penelitian Vagg, Spielberger dan Wasalah (2002) mengungkapkan bahwa efek tingkat organisasi yang baik lebih banyak dan lebih besar dalam besarnya dari efek gender. Karyawan di tingkat organisasi yang lebih tinggi melaporkan bahwa mereka mengalami stres lebih sering saat membuat keputusan penting dan berurusan dengan situasi krisis daripada pekerja melakukan di tingkat bawah, untuk siapa gaji yang tidak memadai dan kurangnya kesempatan untuk kemajuan yang lebih stres. Untuk laki-laki, stres kerja yang lebih kuat terkait dengan kekhawatiran tentang peran mereka dalam struktur kekuasaan dari suatu organisasi, sedangkan karyawan wanita dilaporkan mengalami stres lebih parah ketika ada konflik antara persyaratan kerja dan hubungan keluarga.

Penanggulangan Secara Mandiri. Penanggulangan secara mandiri dapat dilakukan dengan mempraktikkan hal-hal berikut: (1) Tenang, ambil napas panjang dan cobalah untuk santai dan tenangkan diri; (2) Kenali permasalaha, coba kenali akar permasalahannya, apa yang membuat diri resah; (3) Terapi, ikutilah kegiatan sosial sehingga dapat menghindari permasalahan sejenak; (4) Hadapilah, sebaiknya hadapi dan selesaikan agar tidak mengganggu lagi; (5) Atur jadwal, buat jadwal yang harus diperioritaskan lebih dahulu dan tentukan mana yang dapat ditunda. Perkecil peluang untuk timbulnya stres dengan mempersibuk diri sendiri; (6) Diskusi, diskusikan masalah yang menyebabkan timbulnya stres dengan psikolog, (7) Curhat, ceritakan masalah

7 Brotheridge, Celeste M. A Comparison of Alternative Models of Coping: Identifying Relationships Among Coworker Support, Workload, and Emotional Exhaustion in The Workplace, International Journal off Stress Management, 8(1), 2001, 1-14.

\begin{tabular}{|c|c|c|c|c|c|c|}
\hline Volume & Nomor & Edisi & P-ISSN & E-ISSN & DOI & Halaman \\
11 & 2 & Juni 2020 & $2085-7365$ & $2722-3027$ & 10.47625 & $1-10$ \\
\hline
\end{tabular}


yang dihadapi pada keluarga atau pasangan; (8) Buat keseimbangan, stres muncul karena terlalu focus pada pekerjaan, bagilah waktu antara pekerjaan dan keluarga. Melakukan hal-hal bersama keluarga akan membuat kembali segar; (9) Pahami tugas dan kewajiban sebagai karyawan, mungkin inilah yang jelas-jelas akan mengurangi stres yang dialami ditempat kerja. Dengan mengetahui kewajiban akan mampu mengatur waktu dan rutinitas sehingga peluangstres akan semakin kecil.

\section{Skema 4: Dinamika Stress Kerja}

Sumber Stress

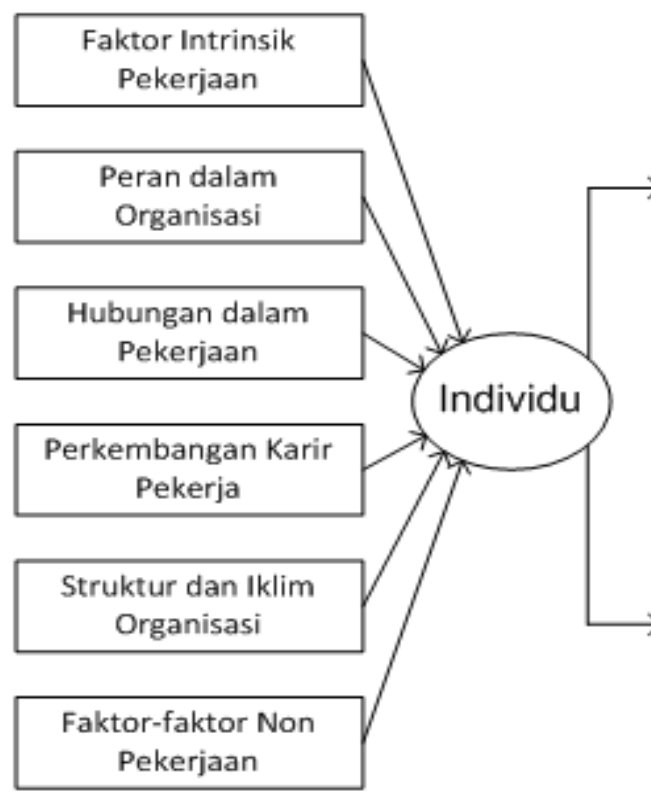

Gejala Stress

Penyakit

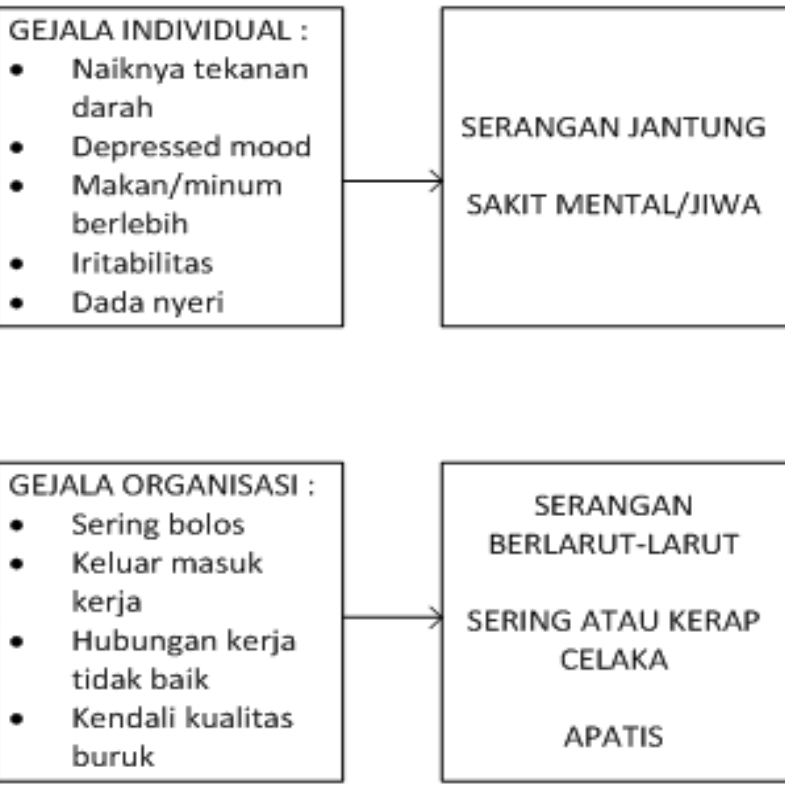

Gambar 2: Dinamika Stress Kerja (Pengertian Tekanan Kerja dan Kepuasan Kerja ${ }^{8}$

Seseorang dapat menggunakan beberapa ukuran untuk menurunkan tingkat depresi yang dialaminya. Dengan demikian, akan dapat berkata saya hari ini saya dapat mengendalikan diri saya sendiri, untuk itu harus: (1) Menyingkirkan masalah yang menyebabkan stress untuk sementara waktu; (2) Keluar dari jadwal yang telah dibuat; (3) Menulis memo untuk diri sendiri; (4) Ganti suasana/lingkungan; (5) Konsentrasi pada pekerjaan hari ini; (6) Cari contoh orang-orang yang sukses dan yang gagal; (7) Hadapi satu persoalan pada satu saat; (8) Mengembangkan hobi baru

\footnotetext{
${ }^{8}$ Basri, 2016.
}

\begin{tabular}{|c|c|c|c|c|c|c|}
\hline Volume & Nomor & Edisi & P-ISSN & E-ISSN & DOI & Halaman \\
11 & 2 & Juni 2020 & $2085-7365$ & $2722-3027$ & 10.47625 & $1-10$ \\
\hline
\end{tabular}


FITRAH

Durnal Studi Pendidikan

\section{KESIMPULAN}

Berdasarkan hasil pembahasan, maka dapat disimpulkan bahwa sebagian peradaban saat ini dirasakan semakin berat dan terkesan kejam, serta membuat setiap orang berupaya untuk berjuang semakin keras dan pantang menyerah untuk menaklukkannya. Dalam perjalanan untuk mencapai kesuksesan, kebahagiaan, dan kekuasaan, manusia sering dihadapkan pada suatu kendala yang biasa disebut sebagai problematika kehidupan/stress. Manusia dapat saja bertahan dengan keadaan ini, tetapi jiwa pada kenyataannya selalu terguncang. Perasaan-perasaan ini ternyata membuat manusia menjadi pesakitan, mudah cemas, sering merasa tertekan, depresi, histeris dalam menyikapi kehidupan,

Diharapkan bagi masyarakat terutama pada lingkungan pendidikan untuk menjaga emosional tetap stabil, agar tidak terjadinya stres yang pada akhirnya menjadi orang yang jiwanya terganggu bahkan memilih jalan yang lebih ekstrim dalam menyikapi kehidupan dengan melakukan bunuh diri agar masalah selesai untuk selamanya.

\begin{tabular}{|c|c|c|c|c|c|c|}
\hline Volume & Nomor & Edisi & P-ISSN & E-ISSN & DOI & Halaman \\
11 & 2 & Juni 2020 & $2085-7365$ & $2722-3027$ & 10.47625 & $1-10$ \\
\hline
\end{tabular}




\section{DAFTAR PUSTAKA}

Agoes, A. Teori dan Manajemen Stress (Kontemporer dan Islam). Malang: Taroda. 2003.

Bastaman, H.D. Psikologi untuk Menemukan Makna Hidup dan Meraih Hidup Bermakna. Jakarta: Raja Grafindo. 2007.

Bond, Dale S; Lyle, Roseann M; Tappe, Marlene K; Seehafer, Roger S; D'Zurilla Thomas J. Moderate Aerobic Exercise, T'ai Chi, and Social Problem-Solving Ability in Relation to Psychological Stress. International Journal off Stress Management. 9 (4), 2002.

Brotheridge, Celeste M. A Comparison of Alternative Models of Coping: Identifying Relationships Among Coworker Support, Workload, and Emotional Exhaustion in The Workplace. International Journal off Stress Management. 8(1), 2001.

Nasrudin, H. Endin. Psikologi Manajemen. Bandung: Pustaka Setia. 2010.

Schafer, Walt. Stress Management for Wellness: Fourth Edition. United State of America: Wadsworth. 2000.

Setyono, Agus; Mudji Rahardjo; Rini Nugraheni; Edi Rahardja. Analisis Faktor-faktor yang Mempengaruhi Job Stres Serta Pengaruh Terhadap Kepuasan Kerja dan Kinerja Salesmen (studi kasus pada PT. Adira Finance Cabang Bangkong Semarang). Jurnal Studi Manajemen \& Organisasi. 4 (2), 2007, http://ejournal.undip.ac.id/index.php/smo. 2020.03.9.

Surya, Mohammad. Bunga Rampai Psikologi Manajemen. Bandung: Ilham Jaya. 1994.

Taylor, Shelley. Health Psychology: International Edition. New York: McGrawHill. 2003.

Tunggal, Amin Widjaja, Manajemen Suatu Pengantar. Jakarta: Rineka Cipta. 1993.

Vagg, Peter R; Spielberger, Charles D dan Wasalah, Carol F. Effects of Organizational Level and Gender on Stres in The Workplace. International Journal off Stress Management. 9 (4), 2002.

\begin{tabular}{|c|c|c|c|c|c|c|}
\hline $\begin{array}{c}\text { Volume } \\
11\end{array}$ & Nomor & Edisi & P-ISSN & E-ISSN & DOI & Halaman \\
\hline
\end{tabular}

